\title{
Cannibalistic crabs respond to the scent of injured conspecifics: danger or dinner?
}

\author{
Matthew C. Ferner*, Delbert L. Smee, Yin P. Chang \\ School of Biology, Georgia Institute of Technology, Atlanta, Georgia, 30332-0230, USA
}

\begin{abstract}
The selective advantage of avoiding lethal predation typically outweighs the benefits of obtaining food. Many aquatic organisms reduce their foraging activity after detecting the presence of injured conspecifics, but responses of cannibalistic animals are less obvious because injury-related cues might attract rather than deter alerted consumers. We investigated the effect of injured conspecifics on the foraging responses of blue crabs Callinectes sapidus, which are ecologically important consumers known for their aggressive behavior and cannibalistic tendencies. In estuarine tidal channels, we presented natural foragers with a choice between baited control traps and baited treatment traps that included an additional odor source. Traps containing an injured blue crab captured significantly fewer blue crabs than paired control traps deployed for periods of up to $18 \mathrm{~h}$. Injured blue crabs that were aged prior to trap deployment confirmed that deterrent cues related to the injury had dissipated within $22 \mathrm{~h}$. Traps containing chemical solutions derived from injured blue crabs elicited avoidance by conspecifics, but neither uninjured blue crabs nor injured stone crabs Menippe mercenaria were deterrent. Together these data demonstrate that blue crabs reduce foraging activity in the presence of odors released from freshly injured conspecifics. Not only should such avoidance responses facilitate survival by distancing unharmed individuals from areas of intense conflict, but the associated changes in blue crab foraging behavior could also have broader ecological consequences through impacts on other trophic levels.
\end{abstract}

KEY WORDS: Foraging tradeoffs · Avoidance behavior · Olfaction $\cdot$ Conflicting cues $\cdot$ Alarm chemical

\section{INTRODUCTION}

Many animals live in environments where they must search for resources in the midst of predators and aggressive competitors. Foraging activities make animals conspicuous and increase their vulnerability to attack, and therefore alerted prey often flee, seek refuge, or reduce feeding in the presence of predators (Alcock 1998, Kats \& Dill 1998). Predator avoidance behaviors clearly benefit survival, but associated periods of restricted foraging are also costly to prey and can result in decreased growth and fecundity (e.g. Fraser \& Gilliam 1992, Peckarsky et al. 1993, Nakaoka 2000). Some animal species reduce the costs of avoidance by evaluating the local level of risk and employing predation-minimizing tactics at appropriate times (Sih 1987, Lima \& Dill 1990).
The most reliable indication of a predatory threat is a signal produced by the predator itself, and prey could minimize costs of avoidance by responding only to these primary cues. However, predators can be stealthy and prey may not detect predator signals quickly enough to avoid being consumed. For example, predators that hunt rapidly could overcome prey before their scent becomes detectable (sensu Kats \& Dill 1998). Cues released from injured conspecifics might instead offer early warning of potential dangers, thus providing unharmed individuals with an opportunity to avoid the fate of prey that had already been attacked (Chivers \& Smith 1998). On the other hand, intraspecific alarm cues might have a dual meaning for cannibalistic predators since the presence of injured conspecifics could represent a meal as opposed to a lethal threat. 
Blue crabs Callinectes sapidus are excellent model organisms for field studies of the foraging responses of cannibalistic predators. In estuaries bordering the eastern United States, blue crabs are voracious omnivores that exert strong consumer pressure on benthic organisms and can have profound effects on estuarine community structure (Virnstein 1977, Hines et al. 1990, Eggleston et al. 1992, Micheli 1997, Silliman \& Bertness 2002). Higher order predators or larger conspecifics appear to regulate blue crab foraging by increasing the risk associated with exposed habitats, thereby encouraging crabs to retreat to more vegetated or sheltered regions of the marsh (Williams et al. 1990, Micheli 1997). Yet even refuge habitats are not completely safe from danger because crowded conditions increase the chance of an aggressive conflict (Mansour \& Lipcius 1991, Clark et al. 1999b). Despite the fact that blue crabs are cannibalistic (Laughlin 1982, Smith 1995, Meise \& Stehlik 2003) and highly aggressive toward conspecifics (Mansour \& Lipcius 1991, Clark et al. $1999 a, b)$, the foraging responses of blue crabs to injured conspecifics have not been examined. A freshly injured crab could signify the presence of a nearby predator or aggressive conspecific, and individuals that detect these cues may respond in a way that lowers the possibility of a deadly encounter. Alternatively, cannibalistic blue crabs might perceive injured conspecifics as a source of food rather than an indication of danger.

We conducted field experiments to determine whether or not foraging blue crabs respond to the scent of injured conspecifics. Following the movements of multiple animals is a formidable task within turbid and spatially complex estuaries, particularly over short time periods or in relation to discrete objects or odor sources. Ultrasonic telemetry has been useful for studies of blue crab foraging behavior (Wolcott \& Hines 1989, Clark et al. 1999a,b), although transmitters can be applied only to a limited number of animals that have been previously handled and released. In an estuary in coastal Georgia, we deployed baited traps to investigate the attraction of blue crabs to various odor sources without the use of tethers, cages, or markrecapture techniques. Results from our experiments showed that blue crabs respond to chemicals released from freshly injured conspecifics in ways that could have important local impacts on other estuarine species.

\section{MATERIALS AND METHODS}

Study sites. Experiments were conducted from June through October 2002 in 3 estuarine tidal channels extending inland from the Wilmington River near Savannah, Georgia (Fig. 1). Preliminary surveys established that each channel was inhabited by blue crabs and accessible by boat over a range of tidal heights. Bathymetric features were estimated using a vesselmounted acoustic depth sounder, revealing that sites were similar to one another and representative of other tidal channels in the region. The entire study area was bordered by salt marsh (Spartina alterniflora) and by occasional private docks extending to nearby coastal islands.

Experimental design. Foraging responses of blue crabs were investigated using traps that consisted of a weighted box $(61 \times 61 \times 50 \mathrm{~cm})$ of rubber coated $4 \mathrm{~cm}$ wire mesh with an entry hole on each side and 2 escape ports to reduce the capture of juveniles. All traps were baited with a single menhaden fish (Brevoortia sp.) after the caudal fin and posterior portion were removed to standardize bait leakiness and mass $(250 \pm 10 \mathrm{~g})$. Treatment traps included an additional odor source within the central bait compartment to provide multiple cues for foraging crabs. There was

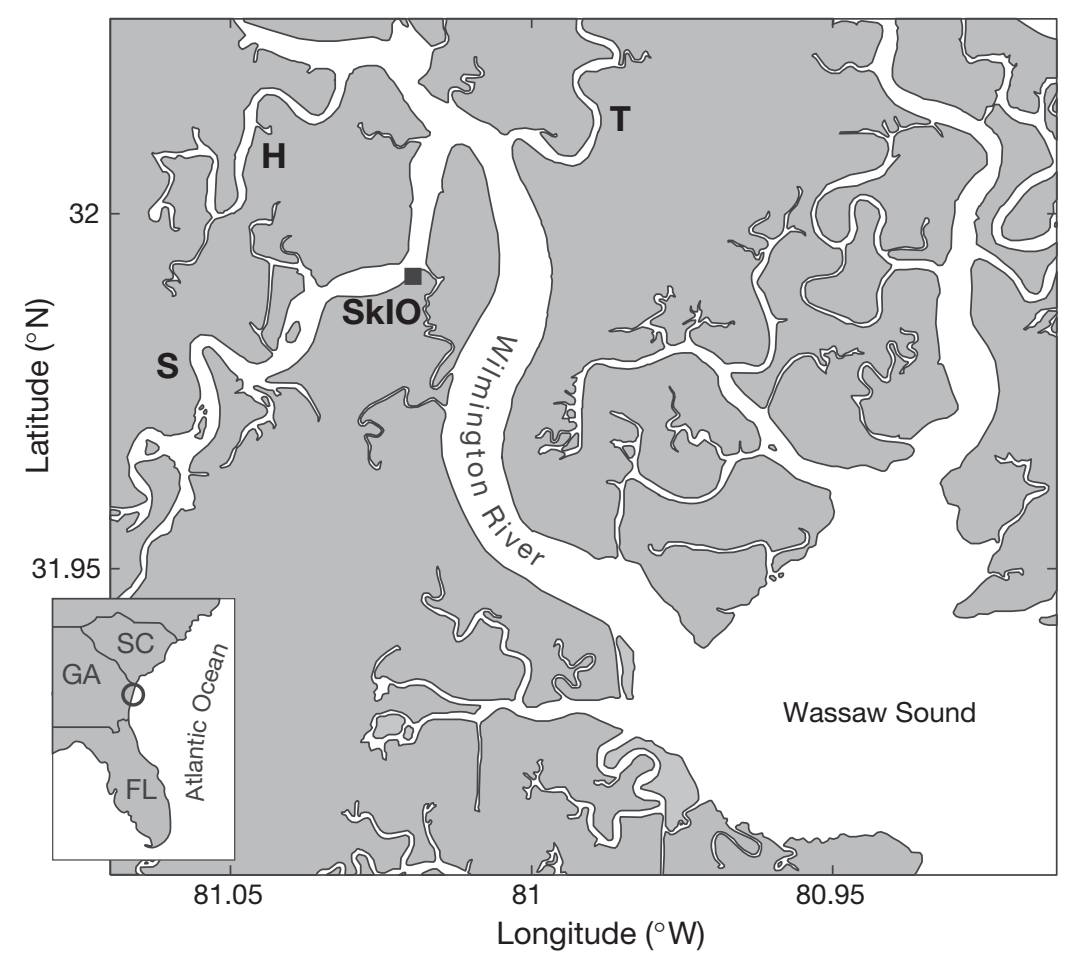

Fig. 1. Map of study sites near Savannah, GA. In each of 3 estuarine tidal channels, trap deployments extended inland from the following locations:

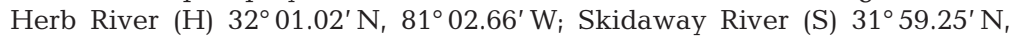
$81^{\circ} 02.10^{\prime} \mathrm{W}$; and Turner Creek (T) $32^{\circ} 00.91^{\prime}$ N, 80 59.41' W. SkIO: Skidaway Institute of Oceanography 
a high degree of spatial variability in the natural distribution of blue crabs, in that certain traps attracted up to an order of magnitude more individuals than other traps deployed within the same tidal channel. To account for this variation, traps were deployed as pairs in which a treatment and control trap were placed about $5 \mathrm{~m}$ apart in similar water depths $(>1 \mathrm{~m})$ and at similar distances from marsh edges. Relative placement of traps (i.e. proximity to channel mouth or smaller tributaries) was randomized within each pair, and adjacent trap pairs were separated by at least $100 \mathrm{~m}$ to reduce interference between replicates. The number of blue crabs that entered treatment versus control traps served as a proxy for trap attractiveness. Different odor sources allowed us to evaluate the specificity and persistence of treatment stimuli.

Testing responses to injured conspecifics. Our principal treatment consisted of injured blue crabs contained within baited traps. Blue crabs were collected from local habitats and transferred to flow-through tanks where they were maintained under estuarine water and fed an ad libitum diet of hard clams Mercenaria mercenaria and ribbed mussels Geukensia demissa. The carapace of each treatment crab was punctured with a thin metal rod (diameter $=6 \mathrm{~mm}$ ). This method imparted consistent and severe damage that ensured release of bodily fluids into the surrounding water. Just before each pair of traps was deployed, 1 freshly injured blue crab was positioned vertically within the central bait compartment of a treatment trap, thus preventing foragers from accessing wounded crabs. Most crabs died within $3 \mathrm{~h}$ of injury and no treatment crabs survived longer than $8 \mathrm{~h}$. Following trap retrieval, the number of blue crabs captured in each trap was recorded and animals were released near the site of collection.

Initially, experimental trap pairs were left in the field for various periods of time (1.5 to $26 \mathrm{~h}$ ) to assess the attractiveness of injured crab treatments and controls over a range of deployment periods. Trap deployments ranging from 1.5 to $8 \mathrm{~h}$ always occurred between dawn and dusk, but longer deployments extended through the night and into the next day. Trap pairs deployed for similar periods were grouped together to facilitate trap placement and retrieval. The exact timing of these trials was distributed haphazardly to avoid biasing patterns of water flow around the traps. Following the analysis of data from this initial experiment, all subsequent trials were conducted for $1.5 \mathrm{~h}$ because sufficient numbers of crabs entered control traps during this period.

Aging injured crabs. Previous observations indicated that approximately $24 \mathrm{~h}$ are required before the maximum number of blue crabs is retained in baited traps (M. C. Ferner unpubl. data), and thus, long trap deployments could compromise the interpretation of catch data due to crabs moving into and out of traps. We aged injured blue crabs prior to placement in traps to determine if the time elapsed since injury affects foraging responses of blue crabs independent of trap deployment period. Blue crabs were injured as previously described and placed in traps suspended at an intermediate depth within a local estuary. Entry holes on the traps were sealed to retain injured crabs and to prevent predators or scavengers from entering the traps. This process exposed treatment crabs to natural tidal flows that should have dispersed leaking fluids at a rate similar to that in our initial experiment. We began the aging process at $4,8,22$, and $36 \mathrm{~h}$ prior to deploying trap pairs so that all treatments could be randomly interspersed during the same $1.5 \mathrm{~h}$ trial period. Trap pairs containing freshly injured crabs (aged $0 \mathrm{~h}$ ) served as a control for the aging process.

Characterizing treatment stimuli. Our final experiment used 3 additional odor sources to test the specificity and chemical nature of cues released from injured crabs. Trap pairs containing these various treatment stimuli were interspersed with pairs containing injured blue crab treatments to confirm that natural foragers were continuing to avoid injured conspecifics. To provide interspecific cues from a sympatric crab species, we tested an alternative treatment trap containing a freshly injured stone crab Menippe mercenaria. These crustaceans forage for bivalves and carrion in estuarine waters and often are captured with blue crabs in the same baited traps. Stone crabs were collected from within our study area and transferred to laboratory holding tanks where they were maintained on the same feeding regimen used for blue crabs. Individual stone crabs were selected to be approximately the same size as the blue crabs previously tested and were injured and placed in treatment traps as described above.

We deployed traps containing uninjured blue crabs to establish that the deterrent effects observed in earlier experiments were indeed caused by crab injury and not by visual or mechanical cues. This live crab treatment also controlled for the possible release of stress-related chemicals due to handling and confinement of treatment crabs. Lastly, we verified that natural foragers were responding to dissolved chemical cues by deploying treatment traps that contained chemical solutions derived from injured blue crabs. Odorants were delivered using a $500 \mathrm{ml}$ plastic bottle with a total of twelve holes (diameter $=4.6 \mathrm{~mm}$ ) arranged in 3 rings of 4 holes encircling the top, middle, and base of the bottle. Each hole was plugged with a $1.5 \mathrm{~cm}^{2}$ piece of rolled cellulose sponge cloth (thickness $=3.5 \mathrm{~mm}$ ) to prevent rapid replacement by estuarine water while allowing most of the treatment solution 
to be released within the $1.5 \mathrm{~h}$ trial period. Before beginning this experiment, delivery bottles were filled with high salinity water $(100 \%)$, placed in the bait compartments of empty traps, and deployed in the Skidaway River (26\%) for 0.75 or $1 \mathrm{~h}$ to estimate the rate of advective exchange. Actual treatment solutions were prepared by soaking 1 injured blue crab in 0.61 of estuarine water for $3.5 \mathrm{~h}$ and then filtering this solution through a $425 \mu \mathrm{m}$ screen. Each batch of treatment solution was prepared from a single injured blue crab to maintain independence among replicates, and 1 clean bottle was filled with solution and placed in each treatment trap immediately prior to deployment.

Statistical analyses. We compared the number of blue crabs captured in paired treatment and control traps to test the general hypothesis that alternate odor sources do not affect blue crab foraging responses. For each of the different treatment types, catch data from paired traps were compared using a Wilcoxon signed ranks test. Data from the first experiment were grouped such that trap pairs deployed for similar periods of time were analyzed together. For the second experiment including 5 interspersed treatments, a Kruskal-Wallis test was also used in order to evaluate the effect of aging period on the proportion of crabs entering treatment traps within each pair. Proportional data were arcsine-transformed prior to ranking observations, and Dunn's test was used to make multiple comparisons (Zar 1996). Critical values were adjusted with a Bonferroni correction to maintain an overall experimental error of $\alpha=0.05$.

\section{RESULTS}

\section{Decrease in treatment effect over time}

The presence of injured blue crabs in baited treatment traps significantly reduced the capture of foraging conspecifics for up to $18 \mathrm{~h}$ (Fig. 2a). Considering only traps deployed for 1.5 to $3 \mathrm{~h}$, the number of blue crabs captured in treatment traps was less than half of the number captured in paired control traps $(n=15$, $\mathrm{p}=0.019$ ). Traps containing injured blue crabs continued to be significantly deterrent when sampled 6 to $8 \mathrm{~h}$ and 15 to $18 \mathrm{~h}$ after deployment $(\mathrm{n}=25, \mathrm{p}=0.035$ and $\mathrm{n}=29, \mathrm{p}=0.001$, respectively). In contrast, trap pairs deployed for at least $22 \mathrm{~h}$ captured comparable numbers of blue crabs in treatment and control traps ( $\mathrm{n}=$ $21, p=0.173)$, suggesting that the deterrent effect of injured crabs decreased over time.

A second experiment using injured crabs that had been aged prior to trap deployment showed that the effectiveness of deterrent cues diminished after $22 \mathrm{~h}$ and was negligible after $36 \mathrm{~h}$ (Fig. 2b). Traps contain- ing freshly injured blue crabs again captured less than half of the number captured in paired control traps ( $\mathrm{n}=$ $15, \mathrm{p}=0.008)$. Injured crab treatments aged for 4 and $8 \mathrm{~h}$ were also deterrent, capturing significantly fewer crabs than in controls $(\mathrm{n}=15, \mathrm{p}=0.004$ and $\mathrm{n}=14, \mathrm{p}=$ 0.006, respectively). In contrast, treatment traps with injured blue crabs aged for 22 and $36 \mathrm{~h}$ prior to deployment captured similar numbers of individuals as in paired control traps $(\mathrm{n}=15, \mathrm{p}=0.139$ and $\mathrm{n}=12, \mathrm{p}=$
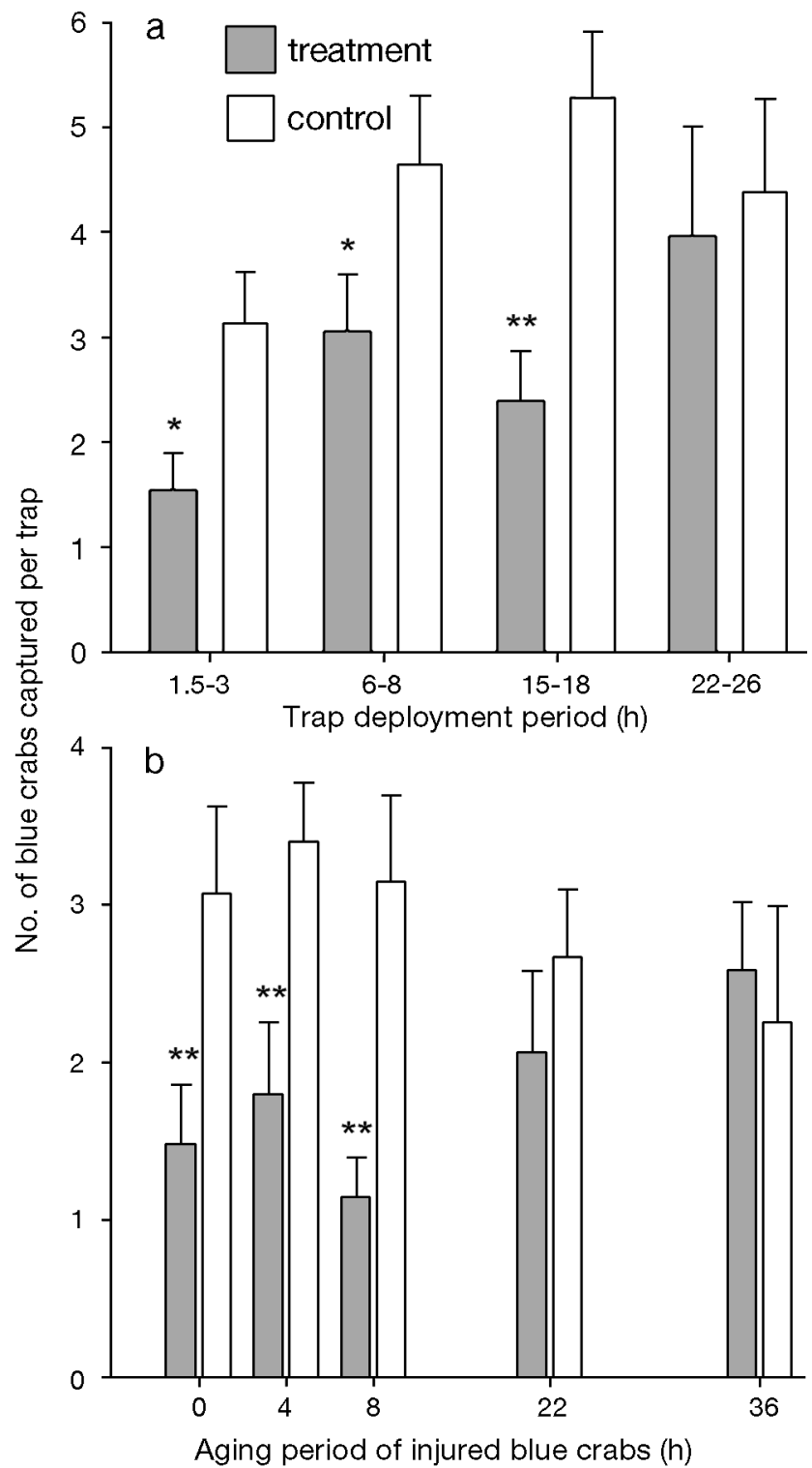

Fig. 2. Callinectes sapidus. Mean number of blue crabs (+SE) captured in paired treatment traps (bait + injured blue crab) and control traps (bait only) showing a change in treatment effect over time. (a) Traps deployed for similar periods were tested together and grouped into 4 independent categories. (b) Trap pairs deployed for $1.5 \mathrm{~h}$ included 5 interspersed treatments containing injured blue crabs that were aged for periods of $0,4,8,22$, or $36 \mathrm{~h}$ prior to trap deployment. * and **: significance at $\mathrm{p}<0.05$ and 0.01 , respectively 
0.594, respectively). There was a significant effect of aging period on the proportion of crabs entering treatment traps within each pair ( $\mathrm{df}=4, H=10.62, \mathrm{p}=$ 0.031). Post hoc comparisons revealed that treatments aged for 22 and $36 \mathrm{~h}$ were significantly different from the 3 shortest aging periods $(p<0.01)$ but not from each other. These data confirm that the deterrent effect of injured blue crabs lessened over time.

\section{Specificity of alarm chemicals}

Results from trap pairs containing either live blue crabs or aqueous solutions derived from injured blue crabs verified that dissolved alarm chemicals were responsible for the observed deterrent effect (Fig. 3a,b). The presence of live (uninjured) crabs did not affect the number of individuals captured in treatment versus control traps (Fig. 3a; $\mathrm{n}=10, \mathrm{p}=0.541$ ), implying that the deterrent signal was unique to injured crabs and that neither visual nor mechanical cues associated with treatment crabs acted to deter conspecifics. Alarm

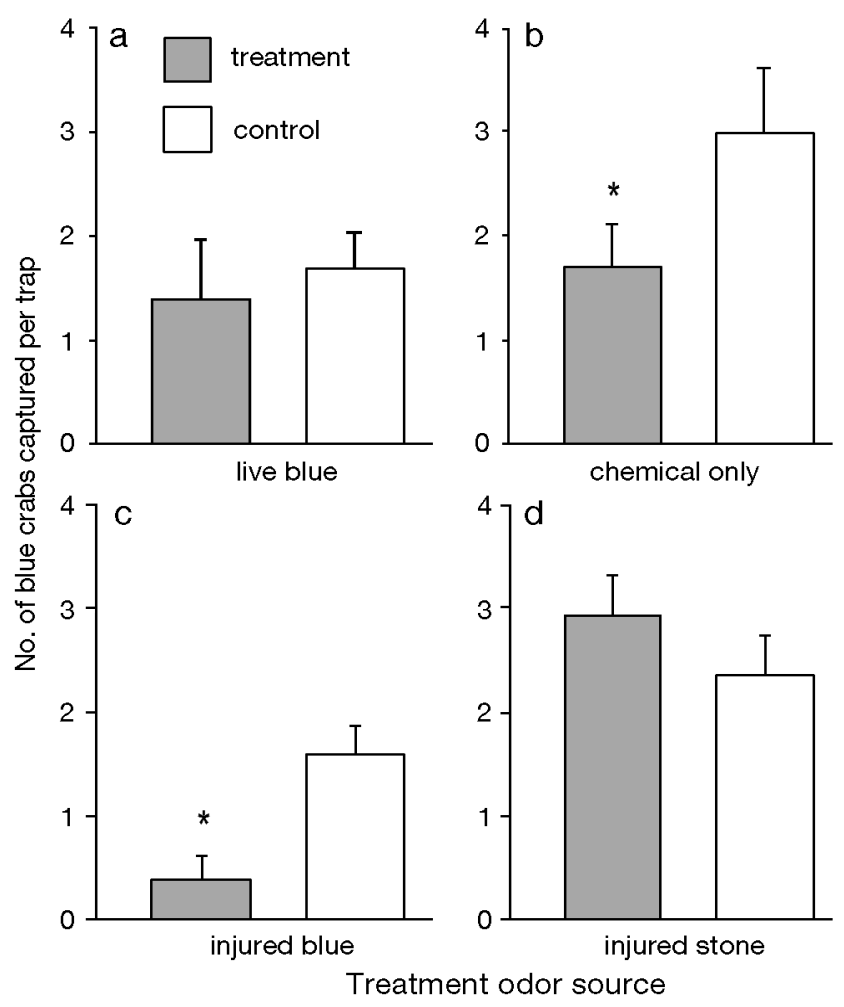

Fig. 3. Callinectes sapidus. Mean number of blue crabs (+SE) captured in paired treatment and control traps deployed for $1.5 \mathrm{~h}$. Control traps containing only bait were paired with treatment traps containing bait plus 1 of 4 additional odor sources: (a) live (uninjured) blue crab, (b) aqueous solution derived from an injured blue crab, (c) injured blue crab, or (d) injured stone crab. Asterisk indicates significance at $\mathrm{p}<0.05$ odors released in the absence of other potentially aversive stimuli resulted in significantly fewer blue crabs entering treatment versus control traps (Fig. $3 \mathrm{~b} ; \mathrm{n}=14$, $p=0.013$ ), further confirming the importance of chemical cues for blue crab avoidance behavior. Preliminary measurements revealed that an average of 65 to $71 \%$ of the test solution was released from each delivery bottle during a standard $1.5 \mathrm{~h}$ trial period. This sufficient but not excessive rate of fluid exchange (mean \pm $\mathrm{SD} ; 0.23 \pm 0.04 \mathrm{l} \mathrm{h}^{-1}$ ) ensured that chemicals derived from injured crabs were dispersed throughout the trial period. Although this treatment probably did not mimic the actual release of odors from injured crabs, it did indicate that chemical cues alone were mediating the avoidance behavior of blue crabs.

We tested the specificity of alarm chemicals by assessing the responses of foraging blue crabs to injured stone crabs. Trap pairs containing injured blue crabs reconfirmed the avoidance behavior previously observed (Fig. 3c; $\mathrm{n}=10, \mathrm{p}=0.025$ ), but substitution of injured stone crabs in treatment traps had no significant effect on the number of blue crabs captured (Fig. 3d; $\mathrm{n}=14, \mathrm{p}=0.295$ ). This lack of deterrence by injured stone crabs suggests that blue crabs respond to alarm chemicals from injured conspecifics and not to a general injury-related cue. Intraspecific responses of stone crabs to this treatment were not evaluated because we did not capture adequate numbers of stone crabs for statistical analysis.

\section{DISCUSSION}

\section{Conspecific chemicals reduce foraging by blue crabs}

Trophic interactions that drive the transfer of energy and materials through communities ultimately depend on the foraging and avoidance behaviors of individual organisms. In many cases the dynamic interaction between positive and negative stimuli should dictate foraging behavior, and in particular, injury-released alarm chemicals are known to inhibit feeding in a variety of aquatic taxa (e.g. Chivers \& Smith 1998, Tomba et al. 2001). These efforts have contributed greatly to our understanding of prey behavior and foraging tradeoffs, yet more field studies are needed to overcome the differences between small-scale laboratory conditions and the true spatial extent of animal foraging in nature. Results from our field experiments demonstrated that naturally occurring blue crabs sacrifice foraging opportunities when detecting chemicals released from freshly injured conspecifics. Compared with baited control traps, fewer individuals entered traps containing the same amount of bait plus an injured blue crab (Figs. 2 \& 3c). Similar responses to aqueous solutions 
originating from injured blue crabs confirmed that dissolved chemicals alone reduced the attractiveness of bait (Fig. 3b), and the lack of an avoidance response to injured stone crabs suggested that foraging blue crabs actively avoid conspecific alarm chemicals (Fig. 3d). Disturbance chemicals such as urine have been shown to alter the behavior of other benthic crustaceans (e.g. Hazlett 1990a,b, Karavanich \& Atema 1998, Schneider \& Moore 2000), but definitive separation of the effects of disturbance and alarm chemicals is difficult because severe injury also should prompt the release of urine and other stress-related compounds. Even so, treatment traps spiked with uninjured blue crabs confirmed that disturbance due to the mere handling and confinement of crabs failed to elicit avoidance responses from foraging conspecifics (Fig. 3a).

Despite the benefits of pursuing a relatively defenseless and nutritious meal such as that present in baited traps, the inherent discrepancy in selective pressure experienced by predators and prey implies that most foragers should value survival over sustenance. This fundamental concept of the life-dinner principle (Dawkins \& Krebs 1979) leads us to hypothesize that because the potential loss of life usually exceeds the cost of missing a single foraging opportunity, prey should be sensitive to alarm cues and willing to accept the costs of predator avoidance. Cannibalistic animals offer an intriguing system in which to examine this assumption, given that their interpretation of seemingly threatening cues is not immediately obvious. For example, a recent laboratory study showed that adult yellow perch Perca flavescens display foraging behavior in response to the same conspecific alarm chemicals that elicit avoidance in juveniles (Harvey \& Brown 2004). Blue crab cannibalism is an important source of mortality for megalopae and juveniles (Hines 2003), and it is reasonable to expect that adults may remain sensitive to conspecific cues. If chemicals emitted from injured blue crabs had advertised a palatable source of nutrition for conspecifics, then our experiments would have been biased in favor of treatments due to the greater amount of potential food contained in treatment traps. Nevertheless, traps containing recently injured blue crabs were a deterrent to foraging conspecifics. These results support the basic notion of the life-dinner principle by confirming that even aggressive cannibals tend to avoid injured conspecifics at the expense of ignoring an attractive food resource.

\section{Persistence of aversive chemical cues}

Changes in the quality or intensity of alarm chemicals should affect avoidance responses, and one goal of this study was to determine the effective lifetime of blue crab alarm chemicals in the field. Preliminary field tests showed that individuals that had died naturally were not deterrent to other blue crabs (M. C. Ferner unpubl. data), although freshly injured crabs deterred conspecifics for up to $18 \mathrm{~h}$ (Fig. 2a). The reduction in deterrence over longer periods presumably resulted from the attraction of crabs after alarm chemicals had dissipated from treatment traps. Aging injured crabs prior to trap deployment allowed us to evaluate the persistence of alarm chemicals and revealed that foraging blue crabs avoid injured conspecifics for at least $8 \mathrm{~h}$ after the moment of injury (Fig. 2b). This period is noteworthy because it exceeds the time required for reversal of tidal flow direction, thereby spanning the entire duration of slack water when odor dispersion would be most restricted. Any predatory or competitive conflicts probably would have concluded within this period, and the lack of a deterrent effect associated with the longest aging periods (22 and $36 \mathrm{~h}$ ) offers convincing evidence that blue crab alarm chemicals lose effectiveness over time (Fig. 2b). Atema \& Stenzler (1977) noted a comparable decline in the activity of gastropod alarm chemicals, but even extremely low concentrations of alarm chemicals could elicit adaptive responses from animals that employ multiple sensory modalities (e.g. Brown et al. 2004).

In addition to being affected by temporal changes in the quality or quantity of alarm chemicals, avoidance responses should reflect the spatial scale at which blue crabs can resolve conflicting cues. Variation in the attraction distance of individual foragers is difficult to measure without visual confirmation of animal movements, but marking and recapture of blue crabs suggests that they can respond to chemical attractants from $>20 \mathrm{~m}$ downstream (M. C. Ferner unpubl. data). Odor tracking behaviors are affected by variation in chemical transport due to hydrodynamics and bathymetry (Weissburg et al. 2002), and the ability of animals to resolve multiple odors should depend on a combination of stimulus mixing and advection. Blue crabs captured in the present study showed distinct responses to odor sources separated by about $5 \mathrm{~m}$. A closer pairing of treatment and control traps may have prevented foragers from distinguishing between traps, but we suspect that blue crabs rapidly adjust their foraging behavior in response to olfactory information. At least within distances of several meters, most foraging blue crabs should avoid areas where recent predation or intraspecific aggression has resulted in serious injury to a conspecific. However, the physical environment affects the transport and detection of chemical cues (Moore et al. 1994, Weissburg et al. 2002), and the distance over which foraging decisions are made will be influenced by environmental characteristics that facilitate or impede the perception of chemical stimuli. 


\section{Ecological implications}

The importance of avoidance behaviors should extend from a subset of the population rather than from every alerted individual. Not all prey animals will reduce their foraging effort when exposed to threatening cues, and previous laboratory studies have revealed that factors such as refuge availability (e.g. Sih \& Kats 1991) and predator diet (e.g. Crowl \& Covich 1990, Jacobsen \& Stabell 2004) can affect the behavioral decisions of prey. Our results illustrate variability in behavioral responses in that some blue crabs entered treatment traps in all conditions tested, regardless of the freshness or effectiveness of alarm chemicals. For example, the most aversive treatments in our initial experiment still captured an average of 2.4 individuals per treatment trap, nearly one-third of the total number of crabs captured in each trap pair (Fig. 2a; 15 to $18 \mathrm{~h}$ deployments). One explanation for this enduring attraction to bait is that even the threat of predation cannot counteract the necessity for obtaining a minimum level of nourishment. Chivers \& Smith (1998) caution that investigations of alarm responses should consider the effects of prey feeding history, and a number of authors have shown that animals deprived of food are more likely to accept an elevated level of risk while foraging (e.g. Stenzler \& Atema 1977, Smith 1981, Hazlett 2003). Despite the lack of a universal response to alarm chemicals, behavioral decisions of the blue crabs that we captured suggest that fewer individuals will forage in areas where recent conspecific injury is detectable. These alarm responses should be particularly effective in areas of high population density or where predation is most intense.

The present study illustrates one general approach for evaluating the behavioral tradeoffs that challenge benthic consumers, and our results demonstrate a possible mechanism behind the foraging decisions of blue crabs. Chemosensory detection of predation risk should allow blue crabs to focus their foraging effort in time and space in order to avoid imminent danger. Behavioral responses to fresh and specific alarm chemicals will alter individual movements and activities in ways that could have strong consequences for other organisms. Blue crabs are important consumers of bivalves, polychaetes, and other crustaceans (Virnstein 1977, Laughlin 1982, Eggleston et al. 1992), and blue crab avoidance of high risk areas or a general reduction in foraging effort might provide a refuge for these potential prey animals. Conversely, preferential foraging in areas where alarm cues are absent could exert severe pressure on local food resources or intensify competition for refuge habitats. Environmental factors affecting resource availability and signal detection should mediate blue crab avoidance responses, and more extensive field tests of animal foraging in relation to distributions of prey and predatory threats will help to clarify the ecological role of alarm chemicals within estuarine communities.

Acknowledgements. The Skidaway Institute of Oceanography supplied research facilities and hosted the Georgia Tech summer course that provided the original incentive for these experiments. We are especially grateful to M. Hay for his candid advice and patience throughout this project. S. Smee and J. Quade generously assisted with pulling crab traps and maintaining animals. Comments by T. Keller and 2 anonymous reviewers greatly improved an earlier draft of this manuscript. An NSF IGERT grant awarded to Georgia Tech supported this research.

\section{LITERATURE CITED}

Alcock J (1998) Animal behavior, 6th edn. Sinauer Associates, Sunderland, MA

Atema J, Stenzler D (1977) Alarm substance of the marine mud snail, Nassarius obsoletus: biological characterization and possible evolution. J Chem Ecol 3:173-187

Brown GE, Poirier JF, Adrian JC (2004) Assessment of local predation risk: the role of subthreshold concentrations of chemical alarm cues. Behav Ecol 15:810-815

Chivers DP, Smith RJF (1998) Chemical alarm signalling in aquatic predator-prey systems: a review and prospectus. Ecoscience 5:338-352

Clark ME, Wolcott TG, Wolcott DL, Hines AH (1999a) Foraging and agonistic activity co-occur in free-ranging blue crabs (Callinectes sapidus): observation of animals by ultrasonic telemetry. J Exp Mar Biol Ecol 233:143-160

Clark ME, Wolcott TG, Wolcott DL, Hines AH (1999b) Intraspecific interference among foraging blue crabs Callinectes sapidus: interactive effects of predator density and prey patch distribution. Mar Ecol Prog Ser 178:69-78

Crowl TA, Covich AP (1990) Predator-induced life-history shifts in a freshwater snail. Science 247:949-951

Dawkins R, Krebs JR (1979) Arms races between and within species. Proc R Soc Lond B 205:489-511

Eggleston DB, Lipcius RN, Hines AH (1992) Density-dependent predation by blue crabs upon infaunal clam species with contrasting distribution and abundance patterns. Mar Ecol Prog Ser 85:55-68

Fraser DF, Gilliam JF (1992) Nonlethal impacts of predator invasion: facultative suppression of growth and reproduction. Ecology 73:959-970

Harvey MC, Brown GE (2004) Dine or dash? Ontogenetic shift in the response of yellow perch to conspecifics alarm cues. Environ Biol Fish 70:345-352

Hazlett BA (1990a) Disturbance pheromone in the hermit crab Calcinus laevimanus (Randall, 1840). Crustaceana 58: 314-316

Hazlett BA (1990b) Source and nature of disturbance-chemical system in crayfish. J Chem Ecol 16:2263-2275

Hazlett BA (2003) The effects of starvation on crayfish responses to alarm odor. Ethology 109:587-592

Hines AH (2003) Ecology of juvenile and adult blue crabs: summary of discussion of research themes and directions. Bull Mar Sci 72:423-433

Hines AH, Haddon AM, Wiechert LA (1990) Guild structure and foraging impact of blue crabs and epibenthic fish in a 
subestuary of Chesapeake Bay. Mar Ecol Prog Ser 67: 105-126

Jacobsen HP, Stabell OB (2004) Antipredator behaviour mediated by chemical cues: the role of conspecific alarm signalling and predator labeling in the avoidance response of a marine gastropod. Oikos 104:43-50

Karavanich C, Atema J (1998) Olfactory recognition of urine signals in dominance fights between male lobster, Homarus americanus. Behaviour 135:719-730

Kats LB, Dill LM (1998) The scent of death: chemosensory assessment of predation risk by prey animals. Ecoscience 5:361-394

Laughlin RA (1982) Feeding habits of the blue crab, Callinectes sapidus Rathbun, in the Apalachicola estuary, Florida. Bull Mar Sci 32:807-822

Lima SL, Dill LM (1990) Behavioral decisions made under the risk of predation: a review and prospectus. Can J Zool 68: 619-640

Mansour RA, Lipcius RN (1991) Density-dependent foraging and mutual interference in blue crabs preying upon infaunal clams. Mar Ecol Prog Ser 72:239-246

Meise CJ, Stehlik LL (2003) Habitat use, temporal abundance variability, and diet of blue crabs from a New Jersey estuarine system. Estuaries 26:731-745

Micheli F (1997) Effects of predator foraging behavior on patterns of prey mortality in marine soft bottoms. Ecol Monogr 67:203-224

Moore PA, Weissburg MJ, Parrish JM, Zimmer-Faust RK, Gerhardt GA (1994) Spatial-distribution of odors in simulated benthic boundary-layer flows. J Chem Ecol 20:255-279

Nakaoka M (2000) Nonlethal effects of predators on prey populations: predator-mediated change in bivalve growth. Ecology 81:1031-1045

Peckarsky BL, Cowan CA, Penton MA, Anderson C (1993) Sublethal consequences of stream-dwelling predatory stoneflies on mayfly growth and fecundity. Ecology 74 : 1836-1846

Schneider RAZ, Moore PA (2000) Urine as a source of conspecific disturbance signals in the crayfish Procambarus clarkii. J Exp Biol 202:837-844

Editorial responsibility: Howard I. Browman (Associate Editor-in-Chief), Storebø, Norway
Sih A (1987) Predators and prey lifestyles: an evolutionary and ecological overview. In: Kerfoot WC, Sih A (eds) Predation: direct and indirect impacts on aquatic communities. University Press of New England, Hanover, NH, p 203-224

Sih A, Kats LB (1991) Effects of refuge availability on the responses of salamander larvae to chemical cues from predatory green sunfish. Anim Behav 42:330-332

Silliman BR, Bertness MD (2002) A trophic cascade regulates salt marsh primary production. Proc Natl Acad Sci 99: 10500-10505

Smith LD (1995) Effects of limb autonomy and tethering on juvenile blue crab survival from cannibalism. Mar Ecol Prog Ser 116:65-74

Smith RJF (1981) Effects of food deprivation on the reaction of Iowa darters (Etheostoma exile) to skin extract. Can J Zool 59:558-560

Stenzler D, Atema J (1977) Alarm response of the marine mud snail, Nassarius obsoletus: specificity and behavioral priority. J Chem Ecol 3:159-171

Tomba AM, Keller TA, Moore PA (2001) Foraging in complex odor landscapes: chemical orientation strategies during stimulation by conflicting chemical cues. J N Am Benthol Soc 20:211-222

Virnstein RW (1977) The importance of predation by crabs and fishes on benthic infauna in Chesapeake Bay. Ecology 58:1199-1217

Weissburg MJ, Ferner MC, Pisut DP, Smee DL (2002) Ecological consequences of chemically mediated prey perception. J Chem Ecol 28:1933-1970

Williams AH, Coen LD, Stoelting MS (1990) Seasonal abundance, distribution, and habitat selection of juvenile Callinectes sapidus (Rathbun) in the northern Gulf of Mexico. J Exp Mar Biol Ecol 137:165-183

Wolcott TG, Hines AH (1989) Ultrasonic biotelemetry of muscle activity from free-ranging marine animals: a new method for studying foraging by blue crabs (Callinectes sapidus). Biol Bull (Woods Hole) 176:50-56

Zar JH (1996) Biostatistical analysis, 3rd edn. Prentice Hall, Upper Saddle River, NJ

Submitted: October 25, 2004; Accepted: May 31, 2005

Proofs received from author(s): August 26, 2005 